\section{The Monetary Policy Innovation Paradox in VARs: A "Discrete" Explanation}

\author{
Michael J. Dueker
}

E mpirical studies in macroeconomicsaccording to Stock and Watson (2001) focus on one or more of the following: (i) describing macroeconomic data, (ii) forecasting macroeconomic data, (iii) quantifying the sources of macroeconomic fluctuations, and (iv) providing analysis of monetary or fiscal policy. Starting with Sims (1980), the vector autoregression (VAR) has played an important role in all four of these interrelated empirical exercises. Assessing policy and the sources of fluctuations involves careful interpretation of a VAR's forecast errors. Consequently, any alteration of the forecasting information set affects the results of policy analysis to the extent to which the forecast errors change. The empirical exercise in this article augments the forecasting information set and investigates whether the conclusions about monetary policy remain the same. In particular, this article suggests that VAR models ought to consider, when specifying the forecasting equations, how monetary policy is implemented through discrete interest rate changes. I find that the mis-specification of the data-generating process for the federal funds rate significantly affects inferences regarding policymakers' behavior in VAR models.

In this sense, this article is similar to Croushore and Evans (2000), which compares VAR analyses of monetary policy using vintage and real-time data in alternative forecast information sets. Their basic finding is that the conclusions concerning monetary policy are quite robust across these two information sets. Although the change in the forecasting information set that I introduce to the VAR is quite modest in comparison with Croushore and Evans's (2000) real-time data, it is sufficient to resolve one nettlesome puzzle in previous VAR analysis of monetary

Michael J. Dueker is a research officer at the Federal Reserve Bank of St. Louis. Mrinalini Lhila provided research assistance.

(c) 2002, The Federal Reserve Bank of St. Louis. policy: how policymakers are thought to proceed after they introduce a policy "innovation." The term policy innovation refers to a surprise change in the federal funds rate that is not part of a systematic response - as implied by the VAR coefficients - to the state of the economy. For some sample periods and methods of decomposing forecast errors into separate shocks - enough cases to constitute a pattern-monetary policy shocks derived from VARs suggest that policymakers respond to a policy innovation by following it with additional policy moves in the same direction.

It is natural to ask why policymakers would systematically react to their own unexpected-and perhaps uncalled for-increase in the federal funds rate with further increases. ${ }^{1}$ We can call this puzzling pattern the "policy innovation paradox." Specifically, the policy innovation paradox appears in the impulse response function of the federal funds rate to a shock to itself. Under the usual assumption that the federal funds rate is set by monetary policymakers, this impulse response function shows the typical response of monetary policymakers to a shock that they themselves induced. The policy innovation paradox appears when this impulse response continues upward for one or more periods after the initial shock before decaying toward zero. If this characterization of policymaker behavior is accurate, it raises a question: What good does it do for policymakers to systematically follow a surprise increase in the federal funds rate with additional increases? These additional increases would not have a surprise element, nor would they be part of a response to other developments in the economy. The policy innovation paradox would amount to an odd custom of monetary policymakers piling additional funds rate increases on top of a surprise increase.

One rather intricate explanation for this seemingly counterintuitive behavior is that policymakers have access to forecasts that are superior to VAR forecasts. It is possible that the VAR model does not characterize enough policy actions as being systematic responses to developments in the economy. What the model calls a policy innovation may actually be a systematic policy response to an inflation threat that VAR forecasts fail to detect. If such an inflation threat only gradually recedes, policymakers

\footnotetext{
1 Note that when one traces the effect of a monetary policy shock for many periods - 48, for example - visual evidence of this phenomenon in the first three or so periods may be difficult to detect in a chart.
} 
might undertake a series of tightening moves to counter it. In the case where the inflation threat goes undetected by the VAR forecasts, the series of tightening policy moves are attributed to an initial policy innovation that is compounded with additional policy moves in the same direction as the innovation. One glaring weakness with this explanation is that the VAR would have to make systematic forecast errors to miss such an inflation threat repeatedly. For this reason, I investigate an alternative explanation in this article.

The idea that policymakers have information beyond what is contained in VAR forecasts also appears in explanations of the "price puzzle." This puzzle arises when an identified VAR suggests that an unexpected tightening of monetary policy leads to an increase in the price level. Many VARs that decompose forecast errors and derive a monetary policy shock exhibit a price puzzle. The generally accepted explanation for the price puzzle is that monetary policymakers can foresee a rise in inflation, causing them to raise interest rates preemptively. When the VAR forecasts fail to predict this rise in inflation, however, the increase in interest rates is attributed to a monetary policy shock. A misleading inference from a VAR that suffers from the price puzzle is that surprise monetary policy tightenings cause inflation to rise. One way to "fix" the price puzzle in such VARs is to add commodity prices to the model. Changes in commodity prices can aid in forecasting changes in the price level that are due to supply shocks, although the relationship between commodity prices and the price level is somewhat loose (Boughton and Branson, 1991). This resolution of the price puzzle is similar to my proposed resolution of the monetary policy innovation puzzle: both claim that crucial information is missing from the forecast information set in VARs that exhibit the puzzle.

The purpose of this article is to suggest that the policy innovation paradox described above is an artifact of not taking into account the discreteness of monetary policy changes when forecasting. I show that a simple adjustment to the VAR forecasting procedure makes the policy paradox disappear. That is, a policy innovation is not usually followed by further policy moves in the same direction. Instead, the policy shock immediately begins to decay toward zero. The starting point for my explanation of the policy innovation paradox is that VARs generally use monthly or quarterly averages of the daily effective federal funds rate as a measure of monetary policy actions (Christiano, Eichenbaum, and Evans, 1999, and the references therein). The averaging of daily rates smooths and tends to cancel idiosyncratic fluctuations in daily rates that have nothing to do with monetary policy. In this article, I examine one simple but overlooked aspect of using a monthly or quarterly average of the daily federal funds rate in VARs: Since 1984, the Federal Reserve consistently has adjusted a target level for the federal funds rate by discrete increments. Such discrete adjustments to the target during a month convey information about how the next month's average of daily rates is expected to differ from this month's average.

It is important to consider how knowledge of a discrete target change contributes to forecasting. Consider two hypothetical target changes: in the first, the target is raised by 25 basis points one-third of the way through a month; in the second, the target is raised by 50 basis points two-thirds of the way through a month. In the current month, the monthly average of the daily rates would be the same either way, other things equal. Thus, if one were to forecast the next month's average based solely on current and past values of monthly averages, the forecast for the next month would be identical in both of these cases. Discrete target changes usually persist, however, so knowledge of a target change of 50 versus 25 basis points would affect one's forecast of the average level in the next month. Nevertheless, VARs that include monthly or quarterly averages of the daily effective federal funds rate have ignored information contained in discrete target changes. This article investigates whether including information from discrete target changes in VAR forecasts materially changes inferences about how policymakers proceed after they introduce a monetary policy innovation.

\section{DISCRETE TARGET CHANGES AND FORECASTS OF THE MONTHLY AVERAGE}

If a month has $N$ business days and a 50-basispoint (bp) increase in the target federal funds rate occurs $N_{i}$ business days into the month, then, other things equal, we would raise our forecast of the next monthly average, $\overline{F F}_{t+1}$, by $N_{i} / N \times 50$ bp above this month's average, $\overline{F F}$. If more than one discrete change takes place within a month, then we would alter the forecast by 


\section{Table 1}

\section{VAR Data Definitions}

$\begin{array}{ll}\text { Inflation } & \begin{array}{c}\text { Monthly chain-type price index, personal consumption expenditures (monthly percent } \\ \text { change, not annualized) }\end{array} \\ \text { Unemployment } & \begin{array}{l}\text { Percent unemployment in civilian labor force, over age } 16 \\ \text { Interest rate }\end{array} \\ \text { Monthly average of daily effective federal funds rate }\end{array}$

$$
Z=\sum_{i} N_{i} / N \times \Delta F F_{t, i}^{T},
$$

where the discrete target changes are denoted $\Delta F F^{T}$. We can include $Z_{t-1}$, the information imparted by discrete target changes during month $t-1$, as an exogenous regressor that helps forecast the dependent variables in month $t$. A key hypothesis is that the coefficient on $Z_{t-1}$ in the federal funds rate equation is equal to one. This value would confirm the belief that the expected value of $\overline{F F}_{t}$ rises one to one with $Z_{t-1}$, and it would indicate that the forecast errors in the VAR depend significantly on information regarding discrete changes in the target federal funds rate.

\section{A BENCHMARK VAR WITH AND WITHOUT ADJUSTMENT FOR DISCRETENESS}

Monthly data since 1984 offer a relatively short sample for a VAR, but this period provides the longest uninterrupted time series on discrete changes to the target federal funds rate (Rudebusch, 1995). The specific sample period is January 1984 to June 2001. To illustrate the puzzle in an uncluttered model, I use Stock and Watson's (2001) benchmark three-variable VAR in levels. They decompose forecast errors into separate orthogonal shocks through a recursive scheme that puts the inflation rate first, followed by the unemployment rate and the average of the daily federal funds rates, with all three of these variables in levels. Specific data definitions are given in Table 1. Twelve lags of all variables are included to purge the residuals of serial correlation at the seasonal frequencies.

As an exogenous variable, we add $Z_{t-1}$ (with no additional lags) to the VAR to include information from discrete target changes. Table 2 reports the coefficients on this discreteness variable. As expected, the coefficient on $Z_{t-1}$ in the federal funds rate equation (1.21) is not significantly different from one (and very significantly different from zero). Here a value of one means that a discrete target change

\section{Table 2}

\section{Coefficient on Discreteness Adjustment}

\begin{tabular}{lc} 
Equation & Coefficient value \\
\hline Inflation & $-0.054(0.102)$ \\
Unemployment & $-0.167(0.097)$ \\
Federal funds & $1.21(0.141)$
\end{tabular}

NOTE: Standard errors are in parentheses.

is expected to raise next month's average of daily rates by the full amount of the discrete change. Although the point estimate of 1.21 is not significantly different from one, an estimate above one might make sense in that target changes tend to be positively correlated across time. Thus, forecasters might anticipate that a discrete change in a given month will be followed by an additional discrete change in the same direction in the next month. Table 2 shows that the discreteness variable, $Z_{t-1}$, is not a significant predictor of either inflation or unemployment, nor is there any reason to expect a direct relationship. In this case, the discreteness adjustment affects only inflation and unemployment through its effect on forecasts of the federal funds rate. Without the exogenous variable, the standard error of the regression in the federal funds rate equation is 0.229 , whereas it drops to 0.192 (about 16 percent lower) when the exogenous variable is included. Tables 3 and 4 give more complete results on the coefficient estimates in the VAR.

One key difference between the two VARs appears in the first two lags of the federal funds rate in the federal funds rate equation. (The other lag coefficients are all small in absolute value and their sum is small, as shown in Tables 3 and 4.) In the model without $Z$ the first two lag coefficients are 1.237 and -0.245 ; the same coefficients equal 0.924 and 0.026 when $Z$ is included. The presence of $Z$ appears to remove the overshooting and oscillatory 


\section{Table 3}

\section{Coefficients for VAR without Discreteness Adjustment}

\begin{tabular}{|c|c|c|c|}
\hline Coefficient & Inflation equation & Unemployment equation & Federal funds equation \\
\hline Inflation $_{t-1}$ & $0.196(0.074)$ & $-0.055(0.072)$ & $0.097(0.123)$ \\
\hline Inflation $_{t-2}$ & $-0.094(0.076)$ & $0.112(0.074)$ & $0.071(0.126)$ \\
\hline $\begin{array}{l}\sum_{i=3}^{12} \text { Inflation }_{t-i} \\
\text { (sum of lag coefficients) }\end{array}$ & -0.455 & 0.163 & 0.831 \\
\hline Unemployment $_{t-1}$ & $-0.014(0.080)$ & $0.746(0.077)$ & $-0.250(0.132)$ \\
\hline Unemployment $_{t-2}$ & $-0.112(0.098)$ & $0.158(0.094)$ & $-0.112(0.162)$ \\
\hline $\begin{array}{l}\sum_{i=3}^{12} \text { Unemployment }_{t-i} \\
\text { (sum of lag coefficients) }\end{array}$ & 0.124 & 0.075 & 0.309 \\
\hline Federal funds $s_{t-1}$ & $0.160(0.047)$ & $-0.043(0.046)$ & $1.24(0.078)$ \\
\hline Federal funds $s_{t-2}$ & $-0.213(0.075)$ & $0.062(0.072)$ & $-0.245(0.124)$ \\
\hline $\begin{array}{l}\sum_{i=3}^{12} \text { Federal funds }_{t-i} \\
\text { (sum of lag coefficients) }\end{array}$ & 0.071 & -0.007 & -0.041 \\
\hline
\end{tabular}

\section{Table 4}

\section{Coefficients for VAR with Discreteness Adjustment}

\begin{tabular}{|c|c|c|c|}
\hline Coefficient & Inflation equation & Unemployment equation & Federal funds equation \\
\hline Inflation $_{t-1}$ & $0.194(0.075)$ & $-0.059(0.072)$ & $0.124(0.104)$ \\
\hline Inflation $_{t-2}$ & $-0.090(0.077)$ & $0.124(0.074)$ & $-0.014(0.106)$ \\
\hline $\begin{array}{l}\sum_{i=3}^{12} \text { Inflation }_{t-i} \\
\text { (sum of lag coefficients) }\end{array}$ & 0.473 & 0.217 & 0.433 \\
\hline Unemployment $_{t-1}$ & $-0.016(0.080)$ & $0.738(0.077)$ & $-0.188(0.111)$ \\
\hline Unemployment $_{t-2}$ & $-0.112(0.098)$ & $0.156(0.094)$ & $-0.094(0.136)$ \\
\hline $\begin{array}{l}\sum_{i=3}^{12} \text { Unemployment }_{t-i} \\
\text { (sum of lag coefficients) }\end{array}$ & 0.127 & 0.084 & 0.242 \\
\hline Federal funds $s_{t-1}$ & $0.174(0.054)$ & $-0.006(0.052)$ & $0.924(0.075)$ \\
\hline Federal funds $s_{t-2}$ & $-0.225(0.078)$ & $0.024(0.075)$ & $0.026(0.109)$ \\
\hline $\begin{array}{l}\sum_{i=3}^{12} \text { Federal funds } s_{t-i} \\
\text { (sum of lag coefficients) }\end{array}$ & 0.067 & -0.016 & 0.020 \\
\hline Discreteness adjustment $Z_{t-1}$ & $-0.054(0.102)$ & $-0.167(0.098)$ & $1.21(0.141)$ \\
\hline
\end{tabular}

dynamics in the federal funds rate that appear in the VAR without $Z$. In both VAR systems, the largest autoregressive root is over 0.99 . The difference is in the oscillatory dynamics, not in the size of the largest root. The overshooting and oscillatory dynamics in the VAR without the discreteness adjustment ought to appear as a hump shape in the impulse response of the federal funds rate to its own shock. 


\section{Figure 1}

Responses of Inflation, Unemployment, and Federal Funds Rate to a Federal Funds Rate Shock

Without Discreteness Adjustment

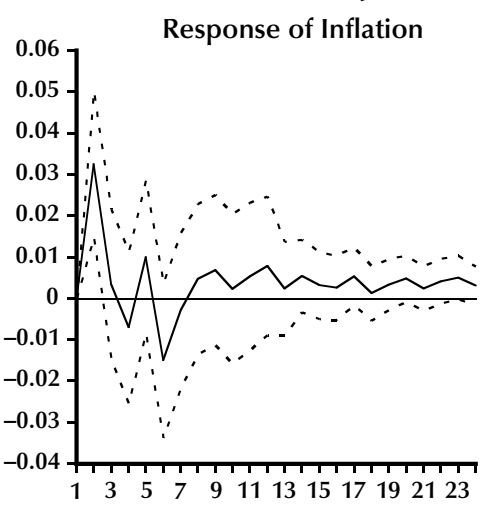

With Discreteness Adjustment

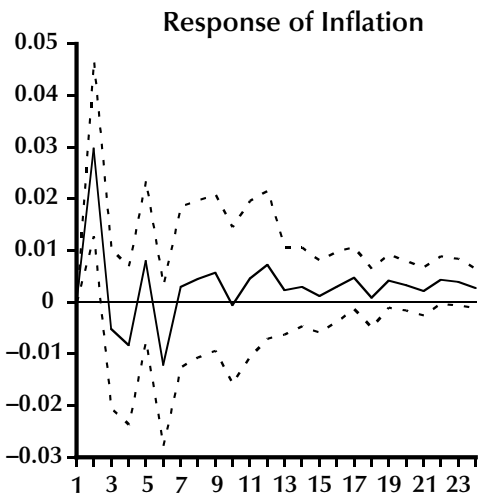

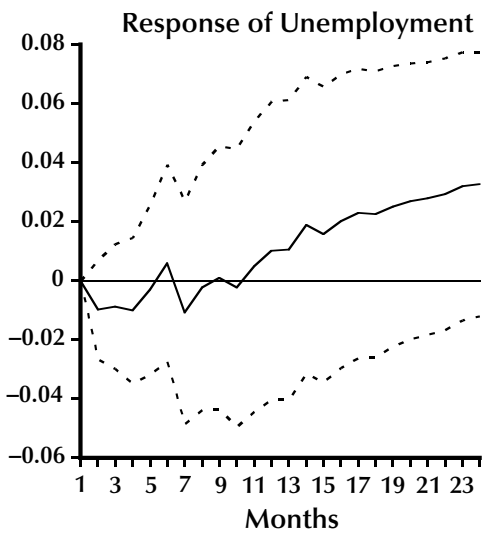
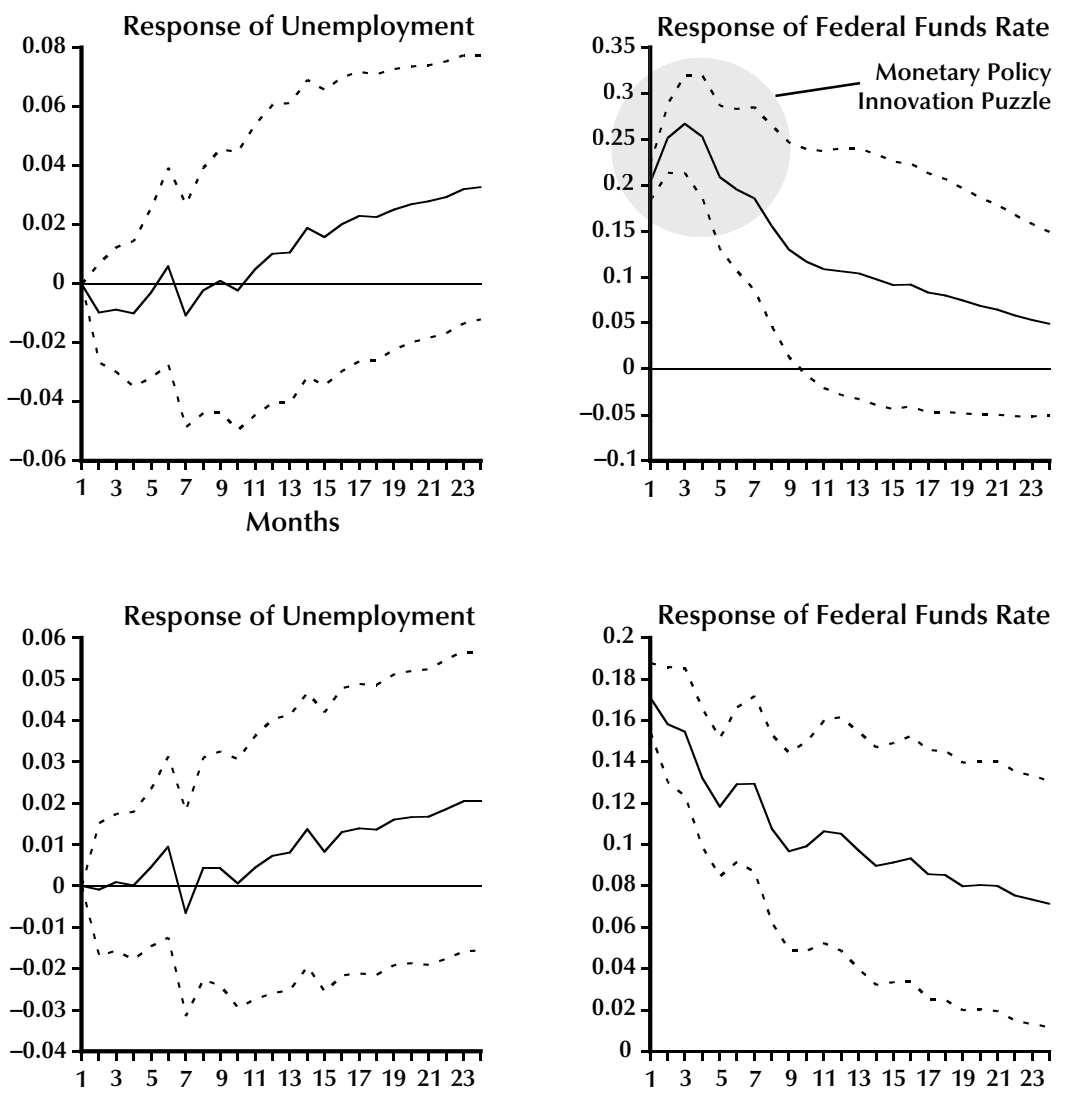

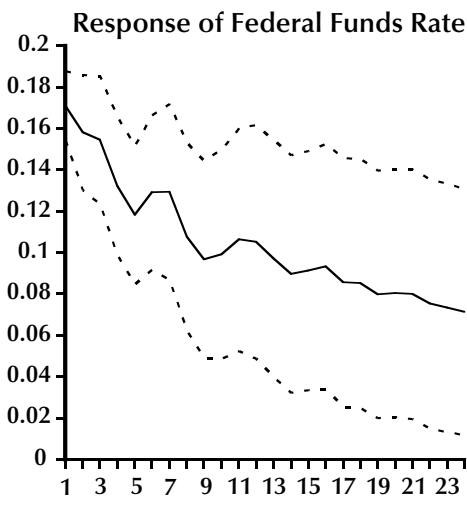

\section{Comparison of Impulse Responses}

The impulse response of the federal funds rate to its own shock shows what monetary policymakers tend to do following a surprise increase in the federal funds rate that is not part of a systematic response to an inflation or unemployment shock-i.e., a policy innovation. Without the exogenous variable in the VAR, the impulse response of the federal funds rate to its own shock displays the policy innovation paradox. The upper right panel of Figure 1 shows that, according to this VAR specification, the monetary policy response to a surprise increase in the federal funds rate is to increase it even more during the next two months. According to this impulse response, the funds rate remains above the initial shock level until five months after the policy innovation. Such a path for the funds rate would be very difficult to rationalize as a typical monetary policy response. In fact, some VARs identify monetary policy shocks with the assumption that a sensible monetary policy response to a policy innovation or nonsystematic change in the policy instrument is to undo the change relatively quickly (Klaeffling, 2001).

An alternative interpretation of this impulse response, however, is that the continued upward movement of the federal funds rate after the initial shock is an artifact of taking monthly averages of a rate that undergoes discrete shifts within the month. The intuition is that monthly averaging breaks a discrete target change into two pieces: a discrete increase in the target rate in the middle of this month will raise this month's average of daily rates by half of the size of the target change; the other half will appear as an increase in next month's average over this month's average. The key is to forecast the next month's average funds rate in a way that uses information from this month's discrete target changewhich is precisely what the exogenous variable $Z$ is designed to do. 


\section{Figure 2}

\section{Variance Decompositions}
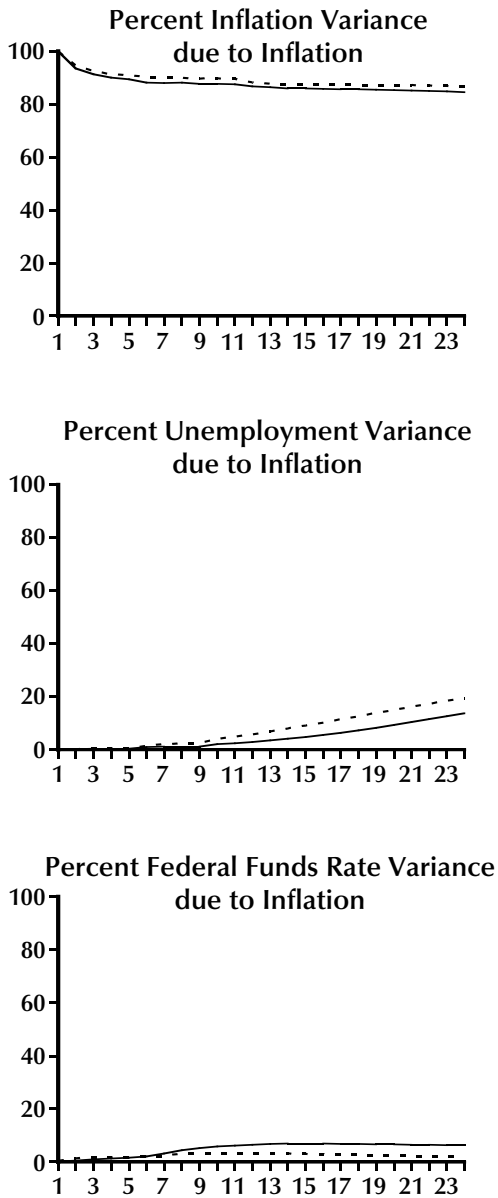
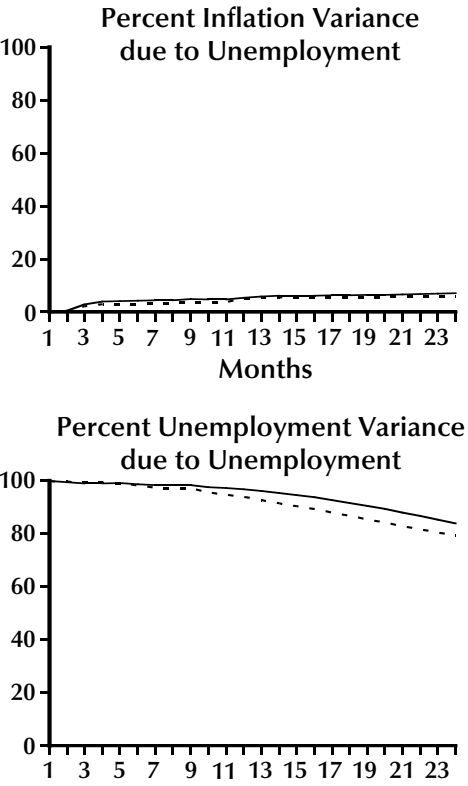

Percent Federal Funds Rate Variance

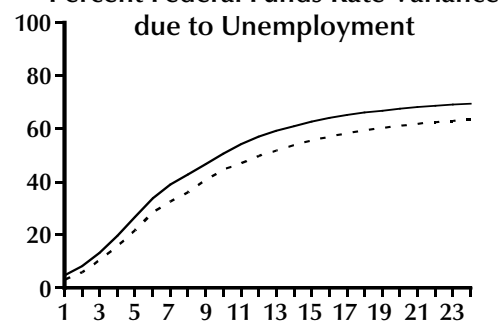

Percent Inflation Variance
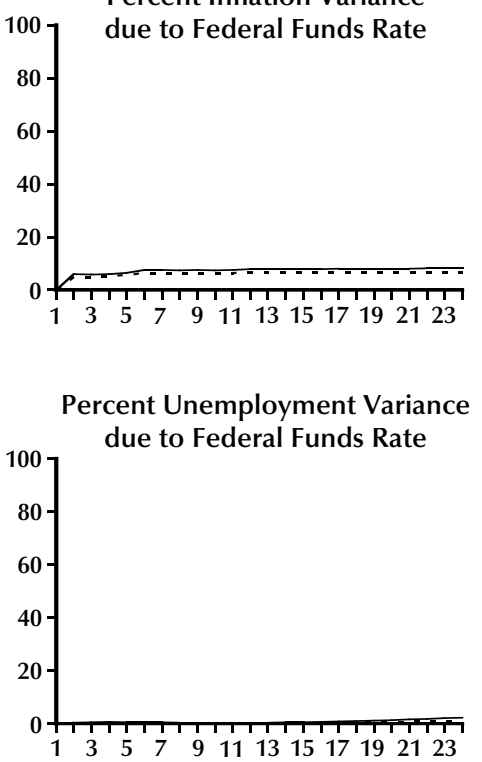

Percent Federal Funds Rate Variance

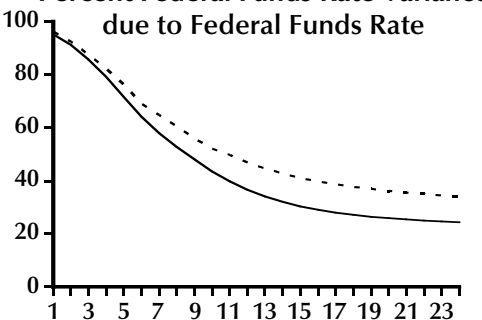

NOTE: Dashed and solid lines represent variance decomposition with and without discreteness adjustments, respectively.

The lower right panel of Figure 1 shows the impulse response of the federal funds rate to its own shock when the exogenous variable $Z$ is included in the system. According to this chart, the response of monetary policymakers to a policy innovation or nonsystematic increase in the federal funds rate is to undo it in a gradual, monotonic fashion. As a description of policymaker behavior, this monotonically declining impulse response is much easier to rationalize than a hump-shaped response that rises further before declining.

Figure 1 also shows the impulse responses of inflation and unemployment to monetary policy shocks. As one might expect, these responses do not differ in any significant manner across the two VAR specifications - with or without the discreteness variable $Z$. We would expect this result given that $Z$ has very low correlations with inflation and unemployment, so that the VAR coefficients are little changed in the presence of $Z$. Therefore, the discreteness adjustment variable in the VAR has little effect on the cumulative impulse response of inflation and unemployment to a federal funds rate shock. Thus, previous VAR analysis of the effects of monetary policy shocks on the economy is left essentially unchanged with this alteration to the VAR model.

\section{Comparison of Variance Decompositions}

While the impulse responses - the response of inflation and unemployment to a given shockdo not differ across the two VAR specifications, the variance decompositions might differ. The discrete- 
ness adjustment variable $Z$ is designed to help predict the federal funds rate, so its presence might alter inferences regarding the relative frequency of different types of shocks. Figure 2 shows the variance decompositions from the two VAR models. The only notable differences are the variances attributable to inflation shocks. With $Z$, a higher proportion of the variance in unemployment is due to inflation shocks, and a lower proportion of the variance in the federal funds rate is due to inflation. But these differences do not affect qualitative descriptions of which shock accounts for most of the variance in a given variable.

\section{CONCLUSIONS AND SUMMARY}

This article considers a straightforward way to make use of information contained in discrete changes to the target federal funds rate when forecasting. The purpose is to show that discreteness is an important feature of the data-generating process for the federal funds rate and that failure to address discreteness affects inferences regarding monetary policymakers' behavior. I apply the approach to a simple three-variable VAR and, not surprisingly, the additional exogenous variable is only a significant predictor of the monthly federal funds rate, not inflation or unemployment. In addition, the discreteness adjustment variable has a coefficient that is not significantly different from one in the federal funds rate equation. We would expect a coefficient of one because the value of this variable is equal to the effect that a discrete target change implies for the change in the daily average from one month to the next, depending on when the change occurs during the month.

This discreteness adjustment nonetheless provides a simple, new explanation for what I call the policy innovation paradox - whereby the reaction of monetary policymakers to their own policy innovation is to push the federal funds rate even farther in the same direction as the initial surprise move. This article shows that the policy innovation paradox disappears once we make use of the discrete- ness information when forecasting the federal funds rate. Thus, the paradox is simply an artifact of using the monthly average of the daily federal funds rate and failing to take account of the information from discrete target changes when forecasting the monthly funds rate. This resolution of the policy innovation paradox does not affect previous VAR results concerning the effects of monetary policy shocks on other macroeconomic quantitiesnamely, inflation and unemployment.

\section{REFERENCES}

Boughton, James M. and Branson, William H. "Commodity Prices as a Leading Indicator of Inflation," in Kajal Lahiri and Geoffrey Hoyt Moore, eds., Leading Economic Indicators: New Approaches and Their Forecasting Records. Cambridge: Cambridge University Press, 1991.

Christiano, Lawrence J.; Eichenbaum, Martin and Evans, Charles L. "Monetary Policy Shocks: What Have We Learned and to What End?" in John Taylor and Michael Woodford, eds., The Handbook of Macroeconomics. Amsterdam: Elsevier Science, 1999.

Croushore, Dean and Evans, Charles L. "Data Revisions and the Identification of Monetary Policy Shocks." Working Paper 2000-26, Federal Reserve Bank of Chicago, September 2000.

Klaeffling, Matt. "Monetary Policy Shocks-A Nonfundamental Look at the Data." Working paper, University of Bonn, October 2001.

Rudebusch, Glenn. "Federal Reserve Interest Rate Targeting, Rational Expectations, and the Term Structure." Journal of Monetary Economics, April 1995, 35(2), pp. 245-74.

Stock, James H. and Watson, Mark W. "Vector Autoregressions." Working paper, Princeton University, March 2001 (forthcoming in Journal of Economic Perspectives).

Sims, Christopher. "Macroeconomics and Reality." Econometrica, January 1980, 48(1), pp. 1-48. 
50 MARCH/APRIL 2002 